\title{
Design and Construction of the LEIR Injection Septa
}

\author{
B.Balhan, P.Bobbio, J.Borburgh, E.Carlier, M. Crescenti ${ }^{11}$, M.Hourican, T.Masson, T. Mueller, \\ A.Prost
}

\section{CERN, Geneva, Switzerland}

\begin{abstract}
The Low Energy Ion Ring (LEIR) transforms long pulses from Linac 3 into high brilliance ion bunches for LHC by means of multi-turn injection, electron cooling and accumulation. The LEIR injection comprises a magnetic DC septum followed by an inclined electrostatic septum. The electrostatic septum has been newly designed and built. The magnetic septum is mainly recovered from the former LEAR machine, but required a new vacuum chamber. Dynamic vacua in the 10-12 mbar range are required, which are hard to achieve due to the high desorption rate of ions lost on the surface. A new interlock and displacement control system has also been developed. The major technical challenges to meet the magnetic, electrical and vacuum requirements will be discussed.
\end{abstract}

${ }^{1)}$ TERA Foundation, Novara, Italy

CERN,

CH-1211 Geneva 23,

Switzerland 


\title{
DESIGN AND CONSTRUCTION OF THE LEIR INJECTION SEPTA
}

\author{
J.Borburgh, B.Balhan, P.Bobbio, E.Carlier, M.Hourican, T.Masson, T.Mueller, A.Prost, CERN, \\ Geneva, Switzerland \\ M. Crescenti, TERA Foundation, Novara, Italy
}

\begin{abstract}
The Low Energy Ion Ring (LEIR) transforms long pulses from Linac 3 into high brilliance ion bunches for LHC by means of multi-turn injection, electron cooling and accumulation. The LEIR injection comprises a magnetic DC septum followed by an inclined electrostatic septum. The electrostatic septum has been newly designed and built. The magnetic septum is mainly recovered from the former LEAR machine, but required a new vacuum chamber. Dynamic vacua in the $10^{-12}$ mbar range are required, which are hard to achieve due to the high desorption rate of ions lost on the surface. A new interlock and displacement control system has also been developed. The major technical challenges to meet the magnetic, electrical and vacuum requirements will be discussed.
\end{abstract}

\section{INTRODUCTION}

The Low Energy Ion Ring (LEIR) transforms long pulses from Linac 3 into high brilliance ion bunches for LHC by means of multi-turn injection, electron cooling and accumulation. Each pulse from Linac 3 is stacked in the horizontal and vertical phase space. To achieve this, the beam from the Linac is injected into LEIR via a $30^{\circ}$ inclined electrostatic septum. This septum is preceded by a magnetic septum, installed in the longitudinally tilted injection line to compensate for the deflection of the beam by the electrostatic septum in the vertical plane. Fig.1 shows the layout of the injection area. The design for both injection septa is based on a beam rigidity of 1.1375 T.m, corresponding to the energy of $4.2 \mathrm{MeV} /$ nucleon for lead ions. To meet the septa requirements [1] (see Table 1) the magnetic septum formerly used in LEAR, could be recovered and adapted. However, the electrostatic septum required a new design.

Table 1: Septa requirements

\begin{tabular}{|l|c|c|}
\hline Septum & Magnetic & Electrostatic \\
\hline $\begin{array}{l}\text { Septum thickness } \\
\text { (apparent) [mm] }\end{array}$ & $7.7(11.4)$ & $0.1(<0.2)$ \\
\hline Deflection angle [mrad] & 175 & 28.9 \\
\hline $\begin{array}{l}\text { Deflection plane w.r.t. } \\
\text { horizontal plane }\end{array}$ & $\begin{array}{c}\text { Tilted } \\
\text { longitudinally } \\
\text { by } 14.5 \mathrm{mrad}\end{array}$ & $\begin{array}{c}\text { Inclined } \\
\text { radially by } \\
30^{\circ}\end{array}$ \\
\hline Dynamic vacuum [mbar] & $10^{-12}$ & $10^{-12}$ \\
\hline
\end{tabular}

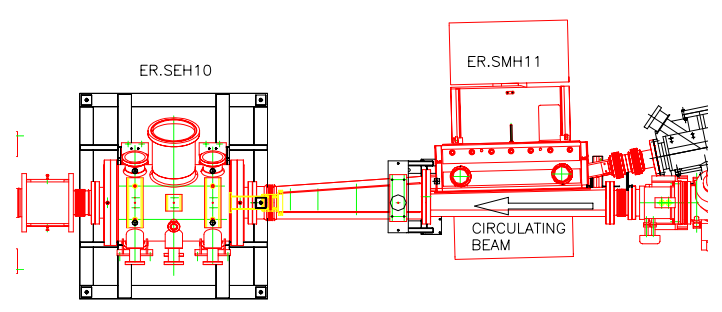

Figure 1: Layout of the injection area.

\section{THE MAGNETIC SEPTUM}

The first septum, ER.SMH11, is installed at the end of the injection line from Linac 3. It is a DC 10-turns magnet. The yoke is in air and surrounds the stainless steel vacuum chamber in the magnet gap. The magnet is displaced vertically by approximately $20 \mathrm{~mm}$ and tilted by $14.5 \mathrm{mrad}$ to allow for the combined longitudinal and transverse injection scheme. The magnet can be split and removed to allow bake-out of the vacuum chamber or to provide access to the magnet coil for maintenance. The magnet is recovered unchanged from the old LEAR machine, and will operate well below its original coil current design value of $2 \mathrm{kA}$. The technical requirements are shown in Table 2, and a cross section in Fig. 2.

Table 2: Magnetic septum specifications

\begin{tabular}{|l|c|}
\hline Integrated magnetic field $\left(\int \mathrm{B} . \mathrm{dl}\right)[\mathrm{T} . \mathrm{m}]$ & 0.199 \\
\hline Gap field $[\mathrm{T}]$ & 0.241 \\
\hline Gap height $[\mathrm{mm}]$ & 55 \\
\hline Gap width between conductors $[\mathrm{mm}]$ & 156.6 \\
\hline Magnet length (physical) $[\mathrm{mm}]$ & 900 \\
\hline Equivalent magnetic length $[\mathrm{mm}]$ & 825 \\
\hline Number of coil turns & 10 \\
\hline Current $(\mathrm{DC})[\mathrm{A}]$ & 1055 \\
\hline Magnet inductance $[\mu \mathrm{H}]$ & 315 \\
\hline Magnet resistance $[\mathrm{m} \Omega]$ & 11.5 \\
\hline Demineralised water cooling requirement $[1 / \mathrm{min}]$. & $<40$ \\
\hline
\end{tabular}

To reduce the fringe field, a $0.35 \mathrm{~mm}$ thick Fe-Ni sheet is used as a magnetic screen and inserted at $0.65 \mathrm{~mm}$ from the yoke next to the septum coil, against the orbiting beam vacuum chamber wall. A non magnetic support plate clamped to the septum coil supports the screen. During bake out, this plate, the magnet and the coil are removed from the vacuum chamber. Finite element calculations show that the magnetic screen reduces the 
fringe field by a factor 10 [2], more than $10^{-4}$ below the gap field, as required [3]. New mechanical supports and vacuum chambers have been built. The vacuum chamber forms an integral part of the coil retaining mechanism.

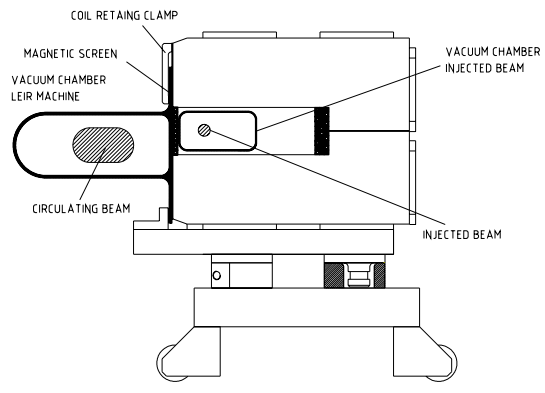

Figure 2: Magnetic septum cross section.

\section{Interlock system}

Water flows, coil temperatures (using thermostats on each individual coil turn) and possible water leaks are continually monitored during operation. All interlocks are grouped together and in the case of failure detection, the power supply is stopped and the cooling water valve closed.

\section{THE ELECTROSTATIC SEPTUM}

The second septum needed for injection into LEIR is the electrostatic septum, ER.SEH10. This septum is installed in the LEIR ring. The septum foil is tilted by $30^{\circ}$ to cope with the combined longitudinal and transverse injection scheme. A new septum has been constructed to cope with the extremely tight vacuum requirements of LEIR. By optimising the internal surface under vacuum and increasing the pumping speed and beam scrubbing, a dynamic vacuum in the low $10^{-12}$ mbar range is expected. The technical specification is shown in Table 3 and a cross section in Fig. 3.

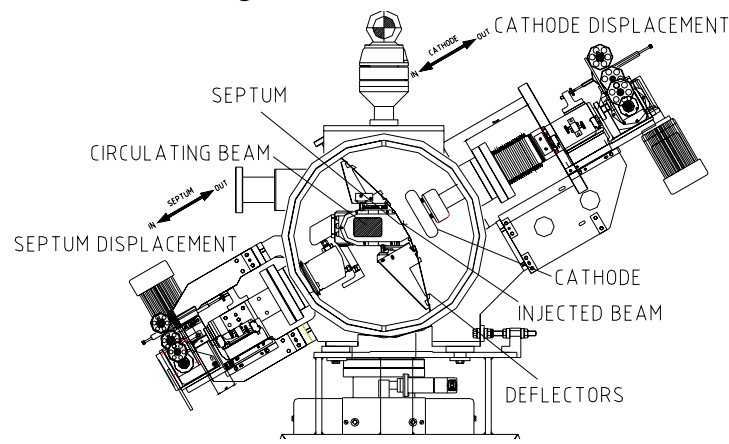

Figure 3: Electrostatic septum cross section

\section{High voltage components}

A 'good field' region of $40 \mathrm{~mm}$ at a $30 \mathrm{~mm}$ gap was specified with a $\pm 0.5 \%$ field uniformity [3]. A finite element analysis of the electric field was carried out to design the High Voltage components such as the cathode and the anode, with its septum foil, the foil support and HV deflectors. A relatively tall cathode of $135 \mathrm{~mm}$ is needed together with deflectors above and below the septum foil support to obtain the required 'good field' region. The results of the calculation (using a $30 \mathrm{~mm}$ gap width) show that a field uniformity of $\pm 0.5 \%$ is achievable in an area of $30 \times 48 \mathrm{~mm}^{2}$, see Figure 4 . For a gap of $40 \mathrm{~mm}$ this area is reduced to $40 \times 36 \mathrm{~mm}^{2}$. For a gap width of $50 \mathrm{~mm}$, only a field homogeneity of $\pm 1 \%$ is achievable in a small area of $50 \times 3.5 \mathrm{~mm}^{2}$.

Table 3: Electrostatic septum specifications

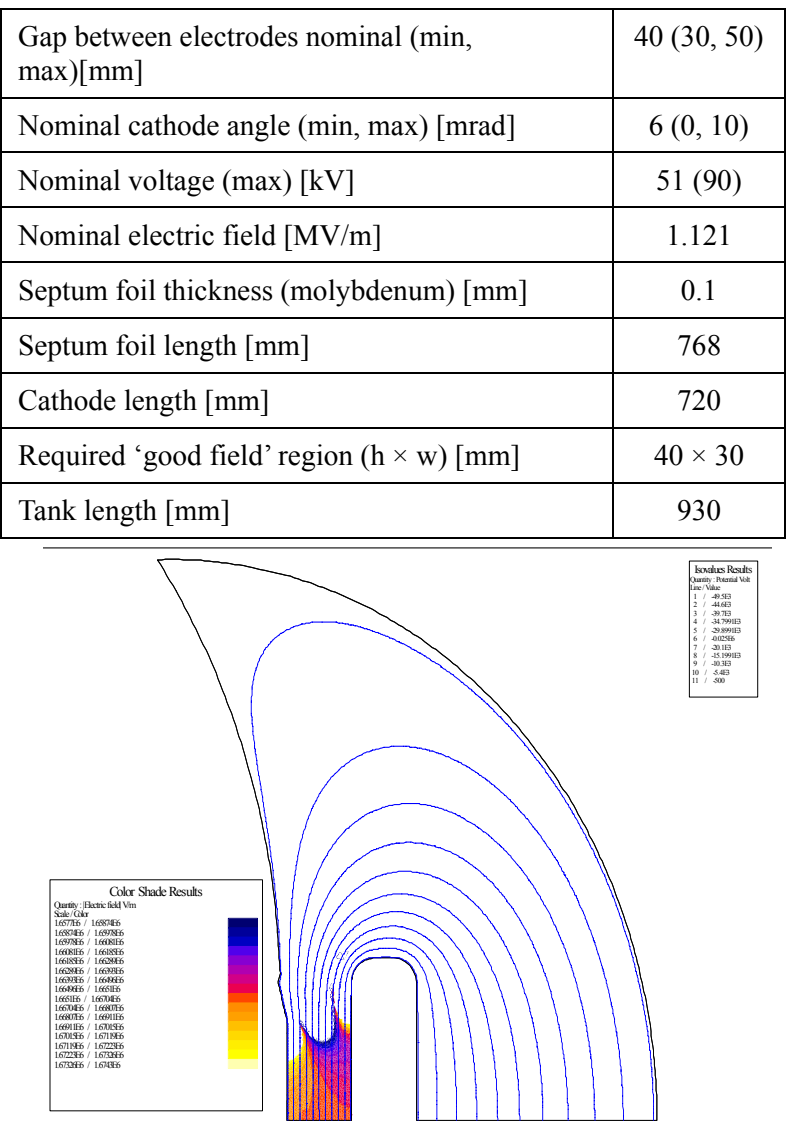

Figure 4: Plot of the field analysis with a $30 \mathrm{~mm}$ gap width. Coloured zones are within $\pm 0.5 \%$ uniformity

The stainless steel ' $C$ ' shaped septum support holds a $100 \mu \mathrm{m}$ thick molybdenum foil which is pre-tensioned to provide a flat surface. The molybdenum foil is fixed to the stainless steel support by means of an assembly that gradually compensates the differences in thermal expansion between the foil and the stainless steel support. This assembly was tested separately. After bake out at $300{ }^{\circ} \mathrm{C}$ the alignment of the foil remains within $100 \mu \mathrm{m}$, so that the effective septum foil thickness as seen by the beam is less than $200 \mu \mathrm{m}$. The molybdenum sheets are hand polished using an average grain size ceramic powder of 2-3 $\mu \mathrm{m}$ which results in a mirror finish. The deflectors mounted above and below the stainless steel support are hand polished and provide protection against titanium sublimation on the active parts of the high voltage assembly.

The high voltage feedthrough, rated at $160 \mathrm{kV}$, has been recovered from ZL LEP separators and uses 3M 
Fluorinert FC 77 for insulation. It is fitted with stainless steel and titanium deflectors. Inside this feedthrough, outside vacuum, a carbon resistor is installed. It decouples the cathode from the supply cable to limit the energy discharged when sparking occurs between the cathode and the septum.

The titanium cathode is mechanically polished. The cathode is supported on ceramic rods fitted with titanium and stainless steel deflectors. The ceramic rods are cleaned by powder blasting, using ceramic powder of $100 \mu \mathrm{m}$ average grain size. The deflectors are dry hand polished, mirror finished.

Following installation in the accelerator the septum will undergo a conditioning period when the voltage is increased progressively to a maximum of $120 \mathrm{kV}$ for the $40 \mathrm{~mm}$ nominal gap. Prior to installation in the accelerator, the septa will be conditioned in the test laboratory up to $150 \mathrm{kV}$ (for the nominal gap).

\section{Vacuum considerations}

In order to reach the extremely low pressures required for LEIR, a NEG coating has been applied to the inner surface of the septum C-shaped support. This increases the available pumping capacity by approximately 1000 $1 /$ min and reduces the desorption yield due to ion impact on the surface.

The vacuum tank is compatible with the vacuum levels required in LEIR and is bakeable at $300{ }^{\circ} \mathrm{C}$. The tank is equipped with "Wheeler" type flanges at each end. All other flanges are of the Conflat type. All vacuum joints are of silver plated copper and bakeable. For pumping purposes the tank is equipped with a $400 \mathrm{l} / \mathrm{s}$ ion pump and 3 Ti sublimators. To measure the vacuum, a BayardAlpert gauge is mounted on the tank. The bake out equipment consists of electrical heating ribbons wrapped around the tank body and Wheeler flanges, together with tailored heating jackets for standard components.

\section{Displacement system}

The positioning systems allow for precise movements in the radial and angular directions for the septum and cathode. Both septum and cathode have mechanically independent displacement systems upstream and down stream. The radial positioning system provides a resolution of $0.06 \mathrm{~mm}$, and the angular system one of $0.01 \mathrm{mrad}$. At bake out temperature $\left(300{ }^{\circ} \mathrm{C}\right)$ the precision slides are protected from excessive heat by the extensive use of titanium supports which form a low heat conductive path between the vacuum tank and the displacement systems. Mounting the slides out of vacuum enables lower pressures to be attained.

In the event of a failure, the high voltage feedthrough can be removed from the tank in situ, without the need to remove the complete tank from the accelerator.

To ensure RF impedance continuity, multi-contacts have been installed between the entry and exit points of the vacuum tank and the septum support. The contacts have been fitted to stainless steel plates to allow rapid dismantling.

\section{High Voltage power converter}

The high voltage for the electrostatic septum is supplied by power converters recovered from LEP 2 ZL electrostatic separators. Two power converters, delivering a maximum of $200 \mathrm{kV}$ at $15 \mathrm{~mA}$, are connected to a high voltage switch. One power converter is used for operation, while the second one serves as a spare. All the components are connected with standard $160 \mathrm{kV}$ LEP cable. The high voltage switch is linked to the septum via a high voltage damping resistor. These components are installed in the LEIR ring close to the septum.

\section{CONTROLS}

The low level controls hardware architecture of LEIR magnetic and electrostatic septa consists of a SIEMENS Simatic S7-400 master Programmable Logic Controller (PLC), connected to the Ethernet TCP/IP network for remote control, interfacing through PROFIBUS-DP fieldbus segments various low-level hardware controllers, based itself on SIEMENS Simatic S7-300 deported input/output channels. The interlock logics, displacement algorithms and high voltage power converter controls are implemented at the PLC master level and the local control and monitoring facilities are provided through an operator console.

The remote control is implemented within the CERN Front End Software Architecture (FESA) framework [4]. The two types of septa are defined as FESA devices described within hierarchical classes, one class for the magnetic septum and another one for the electrostatic septum, reflecting the state and the operational parameters of the equipment.

\section{CONCLUSIONS}

Both septa have been installed in the LEIR ring. The vacuum chamber of the magnetic septum and the interconnecting vacuum chamber between both septa need still to be installed. Both systems will be ready for beam commissioning, planned to take place as from August 2005.

\section{REFERENCES}

[1] Eds. M. Benedikt, P. Collier, V. Mertens, J. Poole, "LHC Design Report: Volume III, The LHC Injector Chain", CERN, Geneva, December 2004, p. 287.

[2] B. Boileau, "Mesures Magnétiques Des Aimants A Septum LEAR SM 11 Et SM12" CERN, PS/BT/Note 82-10.

[3] M. Chanel and Ch. Carli, private communication.

[4] A. Guerrero, J-J Gras, J-L Nougaret, M. Ludwig, M. Arruat, S. Jackson, "CERN Front-End Software Architecture for Accelerators Controls", International Conference on Accelerator and Large Experimental Physics Control Systems - ICALEPCS 2003, Gyoengu, Korea, October 2003. 